\title{
EPISTEMOLOGIAS DO SUL E SOBERANIA AMBIENTAL: A NECESSIDADE DE SUPERAÇÃO DO PENSAMENTO ABISSAL
}

\author{
SOUTHERN EPISTEMOLOGIES AND ENVIRONMENT SOVEREIGNTY: \\ THE NEED FOR OVERCOMING THE ABISSAL THINKING
}

\begin{abstract}
Maria BeATRIz Oliveira da SiLVA
Doutora em Direito Ambiental pelo CRIDEAU (Centro de Estudos Interdisciplinares de Direito Ambiental e Urbanismo) da Universidade de Limoges- França. Professora do Departamento de Direito da Universidade Federal de Santa Maria. Coordenadora do Projeto de Pesquisa"Soberania Ambiental e Autodeterminação dos povos frente ao “Globocolonialismo Verde" (Re) Visitando Conceitos e (Re) Afirmando Direitos e Políticas para o Brasil e América Latina".

Rafaela da CRUz Mello Acadêmica do Curso de Direito da Universidade Federal de Santa Maria (UFSM). Integrante dos Projetos de Pesquisa "Soberania Ambiental e Autodeterminação dos povos frente ao "Globocolonialismo Verde" (Re) Visitando Conceitos e (Re) Afirmando Direitos e Políticas para o Brasil e América Latina" e "A Atuação de Jurisdição Brasileira e Regional no Processo Multidimensional de Desenvolvimento Humano no contexto da Transnacionalização do Direito: os desafios da Policronia e da Assincronia.".

O presente artigo faz parte do projeto "Soberania Ambiental e Autodeterminação dos Povos Frente ao "Globocolonialismo Verde": (Re) visitando Conceitos e (Re) Afirmando Direitos e Políticas para o Brasil e a América Latina" desenvolvido na Universidade Federal de Santa Maria e vinculado ao Grupo de Pesquisas em Direito da Sociobiodiverdidade (GPDS). Resultados parciais do projeto de pesquisa "Soberania Ambiental e Autodeterminação dos povos frente ao "Globocolonialismo Verde" (Re) Visitando Conceitos e (Re) Afirmando Direitos e Políticas para o Brasil e América Latina" desenvolvido no Curso de Direito da UFSM.
\end{abstract}

\section{RESUMO}

0 presente trabalho, que faz parte de uma pesquisa teórica ainda em fase inicial, procura, partindo de um referencial teórico trazido, especialmente, pelo sociólogo português Boaventura de Sousa Santos, verificar como alguns conceitos e definições criados em Conferências Internacionais Ambientais são, em inúmeras vezes, interpretados e aplicados seguindo os entendimentos da epistemologia geral hegemônica dos países do Norte metafórico, em detrimento dos conhecimentos e experiências dos países do Sul metafórico. Neste mesmo viés, far-se-á uma breve análise acerca das mutações do conceito de soberania e a assincronia entre ingerência ecológica e soberania dos Estados, enfocando a questão sob o ponto de vista de um "olhar do sul", o do que Boaventura de Sousa Santos denomina de epistemologias do sul, as quais são conjuntos de intervenções epistemológicas que denunciam a supressão, valorizam saberes e investigam as condições de um diálogo horizontal entre conhecimentos, na busca da superação do denominado pensamento abissal.

Palavras-chave: conferências ambientais; epistemologias do sul; ingerência ecológica; soberania.

\begin{abstract}
This work, which is part of a theoretical research still in its initial stage, looking, from a theoretical brought especially by Portuguese sociologist Boaventura de Sousa Santos, see how some concepts and definitions created in International Environmental Conferences are, in many sometimes interpreted and applied following the general hegemonic understandings of epistemology in the North metaphorical, to the detriment of knowledge and experience in the South metaphorical. In this same vein, it will be far a brief analysis about changes in the concept of sovereignty and the asynchrony between ecological intervention and state sovereignty, focusing on the issue from the point of view of a "look south" than the Boaventura de Sousa Santos calls southern epistemologies, which are collections of speeches denouncing the suppression epistemological, value knowledge and investigate the conditions of a horizontal dialogue between knowledge in the pursuit of overcoming called abyssal thinking.
\end{abstract}

Keywords: environmental conferences; Southern epistemologies; ecological interference; sovereignty.

REDESG / Revista Direitos Emergentes na Sociedade Global - www.ufsm.br/redesg v. 1, n. 2, jul.dez/2012

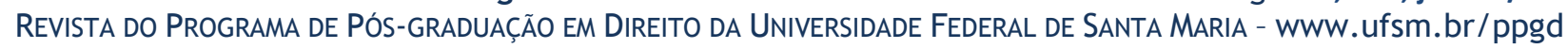




\section{SUMÁRIO}

INTRODUÇAO; 1 EPISTEMOLOGIAS DO SUL E CONFERÊNCIAS INTERNACIONAIS SOBRE MEIO AMBIENTE A CONSTRUÇÃO DE CONCEITOS A PARTIR DO PARADIGMA DOMINANTE; 2 REFLEXOS DA EPISTEMOLOGIA DOMINANTE NO CONCEITO DE SOBERANIA DOS ESTADOS: UMA BREVE ANÁLISE DA SOBERANIA AMBIENTAL; CONCLUSÃO; REFERÊNCIAS.

\section{INTRODUÇÃO}

Em conferências internacionais como a Rio+20, realizada em 2012, no Rio de Janeiro, Brasil, fica clara a diferença de interpretações de conceitos construídos a partir de um relativo consenso. É o caso, por exemplo, de governança ambiental, economia verde, entre outros termos, nos quais as opiniões do Norte (rico) conflitam-se diretamente com as opiniões do Sul (em desenvolvimento).

O paradigma predominante na formulação e interpretação de tais conceitos baseia-se na epistemologia preponderante nos últimos séculos: a epistemologia ditada pelo Norte atendendo aos anseios das politicas colonialistas e capitalistas. De acordo com o que determina Boaventura de Sousa Santos ${ }^{1}$, há alguns séculos dividiu-se o mundo em linhas invisíveis, unilateralmente traçadas e responsáveis por separar experiências e saberes entre úteis e inúteis para a manutenção da epistemologia dominante.

Assim, aquilo que estaria ao lado do Norte metafórico² seria o conhecimento hegemônico, capaz de esgotar o campo de realidade do lado oposto - Sul metafórico -, em que a experiência, o conhecimento e as interpretações seriam inexistentes. Esta é a base do denominado pensamento abissal ${ }^{3}$, que na pós-modernidade ocidental continua a atuar mediante linhas

\footnotetext{
${ }^{1}$ SANTOS, Boaventura de Sousa. Para além do pensamento abissal: das linhas globais a uma ecologia de saberes. In: SANTOS, Boaventura de Sousa; MENESES, Maria Paula. Epistemologias do sul. São Paulo: Almedina, 2010.

${ }^{2}$ Boaventura traz em sua obra a determinação de Norte metafórico e de Sul metafórico, uma vez que estes não se confundem necessariamente com o Norte ou com o Sul geográfico. No interior do Norte geográfico, por exemplo, há grupos e classes sociais que foram e são sujeitos à dominação capitalista, ao passo que no Sul geográfico sempre existiram as elites locais dominantes, denominadas de "pequenas Europas.". SANTOS, Boaventura Sousa; MENESES, Maria Paula. Epistemologias do sul. São Paulo: Almedina, 2010, p.19.

${ }^{3}$ Op. cit., p.33.

REDESG / Revista Direitos Emergentes na Sociedade Global - www.ufsm.br/redesg v. 1, n. 2, jul.dez/2012 Revista do Programa de Pós-graduaçÃo em DiREITO dA Universidade FEderal de SANTA MARIA - www.ufsm.br/ppgd
} 
abissais, negando as práticas do lado do Sul a fim de manter a epistemologia geral hegemônica do Norte.

Esta tentativa de hegemonia estende-se aos recursos naturais fazendo com que a natureza se torne refém das leis de mercado e dos interesses dos detentores do capital, fato que se agudiza ainda mais quando os países "ricos" encontram-se imersos em uma crise sistêmica que também atinge a esfera ambiental - fazendo com que a ingerência ecológica ${ }^{4}$ nos países pobres e em desenvolvimento, detentores de grande parte dos recursos naturais, aumente consideravelmente.

Neste contexto, a partir de pesquisa teórica e de caráter bibliográfico, o objetivo deste trabalho, é abordar, preliminarmente, tendo em vista que faz parte de uma pesquisa em fase inicial, alguns conceitos relevantes, como é o caso do conceito de soberania, procurando estudálo sob o enfoque de um "olhar do sul", ou do que Boaventura de Sousa Santos determina de epistemologias do sul ${ }^{5}$, no sentido de estimular a construção de um arcabouço teórico que sirva para reafirmar o direito ao desenvolvimento sustentável, a autodeterminação dos povos e a soberania ambiental dos países da América Latina.

Para alcançar tal propósito, dividir-se-á o artigo em duas partes: a primeira abordará os conceitos desenvolvidos por Boaventura de Sousa Santos, no sentido verificar a aplicabilidade destes às decisões obtidas em Conferências Internacionais Ambientais, como é o caso da Rio+20 (PARTE 1). Posteriormente, discorrer-se-á acerca das mutações do conceito de soberania, com vistas a abordar sinteticamente a assincronia entre soberania e ingerência ambiental, sob o ponto de vista de um "olhar do sul" ou um "olhar descolonizador" ${ }^{6}$ (PARTE 2).

\footnotetext{
${ }^{4}$ BACHELET, Michel. Ingerência ecológica: direito ambiental em questão. Tradução de Fernanda. Oliveira. Rio de Janeiro: Instituto Piaget, 1995.

${ }^{5}$ SANTOS, Boaventura Sousa; MENESES, Maria Paula. Epistemologias do sul. São Paulo: Almedina, 2010, p.16.

${ }^{6}$ De acordo com Milton Santos, em afirmação feita no documentário Encontro com Milton Santos ou : o mundo visto do lado de cá de Silvio Tendler (2006), descolonizar o olhar é ver o mundo com os próprios olhos, pois o centro dele está em todos os lugares : " o mundo é o que se vê de onde se está ". SANTOS, Milton. Encontro com Milton Santos ou o mundo global visto do lado de cá. Direção de Silvio Tendler. Documentário. Caliban Produções, Brasil, 2006. 


\section{EPISTEMOLOGIAS DO SUL E CONFERÊNCIAS INTERNACIONAIS SOBRE 0 MEIO AMBIENTE: A CONSTRUÇÃO DE CONCEITOS A PARTIR DO PARADIGMA DOMINANTE}

“O problema fundamental em relação aos direitos do homem, hoje, não é tanto o de justificá-los, mas o de protegê-los." Tal lição de Norberto Bobbio ${ }^{7}$ se estende à proteção do meio ambiente, uma vez que este se caracteriza como um direito fundamental de terceira geração. Todavia, a preocupação com a natureza, tanto na esfera interna dos países quanto em âmbito internacional é algo relativamente recente, tanto que o tema meio ambiente constitui um dos principais assuntos da agenda internacional contemporânea ${ }^{8}$.

A constatação de que o meio ambiente ultrapassa fronteiras estatais e que os recursos naturais existentes no planeta são finitos somente se tornou visível em meados do século $X X^{9}$. Contudo, apenas em 1972 ocorreu o primeiro encontro internacional de grande magnitude participação de diversos Estados, organizações internacionais e organizações não governamentais - relativo à proteção internacional do meio ambiente: a Conferência de Estocolmo. Esta teve como resultado a Declaração sobre o Meio Ambiente Humano, importante instrumento internacional de proteção ambiental. Posteriormente, pode-se destacar como relevante a segunda Conferência das Nações Unidas sobre Meio Ambiente e Desenvolvimento, conhecida como ECO-92, na qual o conceito de desenvolvimento sustentável ganhou vigência mundial.

Em 2012, novamente no Rio de Janeiro se realizou a Conferência das Nações Unidas sobre Desenvolvimento Sustentável, mais conhecida como Rio+20. Nesta, os três principais assuntos

\footnotetext{
${ }^{7}$ BOBBIO, Norberto. A era dos direitos. Trad. Carlos Nelson Coutinho. Rio de Janeiro: Campus, 1992.

${ }^{8}$ MAZZUOLI, Valério de Oliveira. Curso de Direito Internacional Público. 5. Ed. São Paulo: Editora Revista dos Tribunais, 2011, p.977.

${ }^{9}$ A primeira manifestação considerável acerca do Direito Internacional do Meio Ambiente ocorreu em uma arbitragem entre Estados Unidos e Canadá, no qual pessoas e empresas localizadas em Washington (EUA) motivaram reclamações contra a fumaça tóxica de dióxido de enxofre produzida pela Trail Smelter, na Columbia Britânica (Canadá) e que causava danos à população estadunidense. Apesar de existirem diversas sentenças prolatadas por tribunais locais apontando o problema e condenando os responsáveis, diante da inércia no cumprimento do que fora determinado judicialmente e da manutenção da poluição, o governo estadunidense, em nome próprio, postulou uma série de reivindicações contra o Canadá, por meio de um tribunal ad hoc. 0 resultado da sentença, datada de 1941, elaborou a base para a formulação do princípio 21 da Declaração de Estocolmo, qual seja, "nenhum Estado tem o direito de usar ou de permitir o uso de seu território de tal modo que cause dano à outro Estado". Ibidem.

REDESG / Revista Direitos Emergentes na Sociedade Global - www.ufsm.br/redesg v. 1, n. 2, jul.dez/2012 ReVISTA do Programa de Pós-graduação em DiReito da Universidade Federal de SANTA MARIA - www.ufsm.br/ppgd
} 
discutidos foram: a avaliação do cumprimento dos compromissos acordados na ECO 92, a economia verde e a arquitetura institucional para o desenvolvimento sustentável.

Uma das constatações visíveis, consoante o documento $A$ sustentabilidade do desenvolvimento sustentável 20 anos após a Cúpula da Terra: avanços, brechas e diretrizes estratégicas para a América Latina e o Caribe (2012), é que, desde 1992 o desenvolvimento sustentável instalou-se como conceito no contexto das políticas públicas de diversos países na medida em que as legislações e instituições dedicadas ao meio ambiente se aperfeiçoaram. A despeito de polêmicas envolvendo o termo, os direitos e deveres sobre o meio ambiente são consagrados na maioria das constituições políticas dos países, confirmando o alcance mais amplo do direito ao desenvolvimento com a integração da variável ambiental.

No entanto, no sistema capitalista, sobretudo na atual fase deste, o neoliberalismo, tudo se reduz à mercadoria, sendo que a natureza também não escapa desta premissa, na medida em que o sistema procura aferir aos bens públicos características de bens privados, seguindo a lógica do modo de produção dominante. De acordo com Jean-Marie Harribey ${ }^{10}$ pela primeira vez na história, o capitalismo produz simultaneamente duas degradações: uma de ordem social, uma vez que a pobreza e a miséria não recuam no mundo, apesar de um considerável crescimento das riquezas produzidas e outra de ordem ambiental, de ameaças ao meio ambiente.

Evidentemente, a degradação ambiental é oriunda do funcionamento do modo de produção capitalista (de rentabilidade máxima do capital investido sob baixos custos) e do modelo de consumo da sociedade atual. Este modelo de crescimento e desenvolvimento não é natural da espécie humana, pelo contrário, é típico do capitalismo, em que a organização econômica gira em torno da produção de lucro e não da satisfação de necessidades.

Está-se, portanto, diante de uma crise ambiental, visto que a extração de recursos naturais ou geração de dejetos é maior do que a capacidade de reproduzi-los ou reciclá-los ${ }^{11}$. Frente a esta constatação, verifica-se que o termo "desenvolvimento sustentável" foi apropriado pela economia dominante e esvaziado, em grande parte, do seu potencial reformador.

10 HARRIBEY Jean-Marie. Marxismo ecológico ou ecologia política marxiana? Dictionnaire Marx contemporain (sob a direcção de Bidet J., Kouvélakis), Paris, PUF, Actuel Marx Confrontation, 2001, p. 183-200. Trad. Fernando Ic. Martins. Disponível em: <http://resistir. info/ ambiente/ecologia_politica.html\#asterisco>. Acesso em: 16 abr. 2012.

${ }^{11}$ FOLADORI, Guilhermo Ricardo. 0 Capitalismo e a crise ambiental. Raízes - Revista de ciências sociais e econômicas, $\quad$ v. 19, p. 117-125, maio 1999. Disponível em: <http://www.ufcg.edu.br/ raizes/artigos/Artigo_42.pdf >. Acesso em: 16 jul. 2012. 
$\mathrm{Na}$ Rio+20, a expressão economia verde surge no sentido adequar o conceito de desenvolvimento sustentável à nova fase da economia capitalista. Segundo o relatório do PNUMA (Programa das Nações Unidas para o Meio Ambiente) ${ }^{12}$, a economia verde é um veículo para que o desenvolvimento sustentável ocorra de maneira plena. Entretanto, mesmo com os benefícios apontados pelo relatório, tal conceito é vazio e trata a natureza como se fosse um capital (valoriza o meio ambiente para mercantilizá-lo), sendo uma maneira de o capitalismo reverter ou no mínimo amenizar - os efeitos de sua crise econômica.

Neste viés, a própria Cúpula dos Povos, movimento organizado pela sociedade civil global e realizado em 2012, concomitantemente à Rio+20, apresentou como conclusão precípua o fato de que a economia verde significa um controle entre os territórios e sobre os bens comuns da humanidade, na medida em que todos os ciclos vitais da natureza serão submetidos às regras de mercado, ao domínio da tecnologia, da mercantilização do meio ambiente e de suas funções.

Desta maneira, a solução para a crise ambiental sugerida pela Rio+20 mantém aquilo que Boaventura de Sousa Santos chama de pensamento abissal ${ }^{13}$, uma vez que, o conceito proposto como alternativa aos problemas ocasionado pela crise é permeado pelas epistemologias dominantes advindas do Norte que sustentam o modelo capitalista, patriarcal e colonialista ${ }^{14}$. Boaventura destaca que um dos grandes problemas da pós-modernidade é o denominado pensamento ortopédico ${ }^{15}$, no qual problemas "fortes" emergem com frequência, mas são respondidos com respostas ou alternativas "fracas", corroborando para a continuidade da hegemonia da dominação do Norte em relação ao Sul.

12 O Programa das Nações Unidas para o Meio Ambiente apresentou o relatório Rumo a uma Economia Verde, no qual o conceito de economia verde e a fundamentação para sua aplicação estão descritos. Segundo o Pnuma, o termo economia verde é um veículo para que o desenvolvimento sustentável ocorra, remetendo à ideia de melhoria do bem-estar humano e da igualdade social ao mesmo tempo em que propõe a redução, de modo significativo dos riscos ambientais e da escassez ecológica. PNUMA. Rumo a uma Economia Verde: caminhos para o desenvolvimento sustentável e a erradicação da pobreza. Relatório. Disponível em <http://www.unep.org/greeneconomy/Portals/88/documents/ger/ GER_synthesis_pt.pdf>. Acesso em 10. out. 2012.

${ }^{13}$ SANTOS, Boaventura de Sousa. Para além do pensamento abissal: das linhas globais a uma ecologia de saberes. In: SANTOS, Boaventura de Sousa; MENESES, Maria Paula. Epistemologias do sul. São Paulo: Almedina, 2010.

${ }^{14}$ Pertinente lembrar, como bem explica Boaventura, que o fim do colonialismo político enquanto forma de dominação não significou o fim das relações sociais extremamente desiguais geradas por ele. Ibidem.

${ }^{15}$ SANTOS, Boaventura de Sousa. Um Ocidente não-ocidentalista? A filosifia à venda, a douta ignorância e a aposta de Pascal. In: SANTOS, Boaventura de Sousa; MENESES, Maria Paula. Epistemologias do sul. São Paulo: Almedina, 2010, p. 528.

REDESG / Revista Direitos Emergentes na Sociedade Global - www.ufsm.br/redesg v. 1, n. 2, jul.dez/2012 Revista do Programa de Pós-graduaçÃo em DiREITO dA Universidade FEderal de SANTA MARIA - www.ufsm.br/ppgd 
A ideia de economia verde dentro do paradigma da epistemologia dominante encontra no mínimo uma contradição: conforme se sabe, a causa de um problema não pode ser a sua solução. Logo, se as causas da crise ambiental estão totalmente vinculadas às desigualdades oriundas do sistema capitalista, a solução para os problemas ambientais não pode ser só a economia verde. Tanto o desenvolvimento sustentável quanto o seu "veículo", devem corresponder ao processo de crescimento de uma economia associado à erradicação da pobreza, distribuição de renda e combate aos mais diversos tipos de desigualdades.

As consequências da crise ambiental não são idênticas quando se está diante de uma globalização desigual. Assim, aceitar que os países ricos dividam injustamente a responsabilidade pela crise ambiental com os países pobres implica em um congelamento das relações desiguais existentes no plano internacional. De outra forma, tentar impor aos países do sul a reprodução do modelo predatório e degradador adotado pelos países do norte, levaria o planeta a um colapso ambiental sem precedentes ${ }^{16}$.

Neste sentido, segundo Boaventura, para a manutenção do próprio sistema e dos interesses do colonialismo e do capitalismo ocorreram e ocorrem os chamados epistemicídios ${ }^{17}$, ou seja, a supressão dos conhecimentos locais que contrariem os interesses da epistemologia dominante. Obviamente, em função da própria dimensão territorial do planeta e das diferenças culturais existentes, é inconcebível pensar que existe unicamente uma epistemologia no globo.

0 mundo é diverso e, justamente nesse contexto, surge a ideia das chamadas epistemologias do sul, as quais são conjuntos de intervenções epistemológicas que denunciam as supressões, valorizam os saberes que resistiram com êxito e investigam as condições de um diálogo horizontal entre conhecimentos.

De acordo com o sociólogo português, ainda existe a predominância de um pensamento abissal, ou seja, aquele em que, de modo unilateral, definem-se linhas invisíveis que dividem experiências, saberes e atores sociais entre úteis e inúteis. Logo, o que está "deste lado da linha” (lado do Norte) além de generalizar o modo de vida da civilização “desenvolvida” também

\footnotetext{
${ }^{16}$ FURTADO, Celso. Reflexões sobre a crise brasileira. In: ARBIX, Glauco et al. (orgs.). Razões e ficções do desenvolvimento. São Paulo: UNESP; Edusp, 2001.

${ }^{17}$ Op. cit. p. 530 .

REDESG / Revista Direitos Emergentes na Sociedade Global - www.ufsm.br/redesg v. 1, n. 2, jul.dez/2012 Revista do Programa de Pós-graduação em Direito da Universidade Federal de SanTa MaRIa - www.ufsm.br/ppgd
} 
esgota o campo de realidade daquilo que se encontra "do outro lado da linha" (lado do Sul), desperdiçando inúmeras experiências ${ }^{18}$.

Tal postulado, consoante já fora mencionado, aplica-se às inúmeras discussões visualizadas em Conferências Internacionais Ambientais. Nestas, diversos conceitos, como é o caso do próprio desenvolvimento sustentável e da economia verde são, inúmeras vezes, permeados da lógica ou aplicados sob a lógica da epistemologia dominante, contribuindo para o aumento das desigualdades.

$\mathrm{Na}$ Rio +20 o que se visualizou foi que os governos de países centrais do capitalismo não parecem dispostos a assumir metas de sustentabilidade que prejudiquem os ganhos lucrativos de grandes corporações ${ }^{19}$. Sabe-se, entretanto, que uma das formas para garantir o direito ao desenvolvimento e atender as necessidades dos povos juntamente com o direito a um meio ambiente ecologicamente equilibrado é não ver o desenvolvimento sustentável e a economia verde somente como propostas governamentais dissociadas do projeto de desenvolvimento. Se assim o for, a proposta de uma "economia verde" se traduzirá, na verdade, em um "capitalismo verde", no sentido da transformação da preservação ambiental em uma fonte de lucro.

Por isso, como uma alternativa a tal problema, encontra-se a proposta de Boaventura de cosmopolitismo subalterno ${ }^{20}$, que se manifesta através das iniciativas e movimentos que constituem uma globalização contra hegemônica. Esta permite a emergência de um pensamento pós-abissal, de superação da monocultura da ciência moderna proposta pela epistemologia ditada pelo Norte, através de um diálogo produtivo entre os dois lados das linhas invisíveis.

O momento de crise estrutural e sistêmica do capitalismo é uma excelente oportunidade para avançar nas contradições do sistema com o intuito de ultrapassá-lo. O capitalismo tende a sobreviver às crises e reconstituir-se em novas bases, porém, a intensificação das lutas por novas relações políticas, demográficas e culturais em momentos de crise constituem oportunidades de transformações.

Essas transformações devem levar em consideração que as diferenças na globalização, o direito à autodeterminação e à soberania de um país sobre seus recursos naturais e seu futuro estão no centro do direito ao desenvolvimento. Assim, muitas vezes aplica-se o discurso de

\footnotetext{
${ }^{18}$ SANTOS, Boaventura de Sousa. Para além do pensamento abissal: das linhas globais a uma ecologia de saberes. In: SANTOS, Boaventura de Sousa; MENESES, Maria Paula. Epistemologias do sul. São Paulo: Almedina, 2010.

${ }^{19}$ BAVA, Silvio Caccia. Impasse na Rio +20. Le Monde diplomatique Brasil. Ano5/Número 59, 2012.

${ }^{20}$ Op. cit. p. 49.

REDESG / Revista Direitos Emergentes na Sociedade Global - www.ufsm.br/redesg v. 1, n. 2, jul.dez/2012 Revista do Programa de Pós-graduação em DireIto da UnIVERSIDAde Federal de SANTA MARIA - www.ufsm.br/ppgd
} 
globalização para justificar ingerências ambientais dos "países ricos" nos "países pobres" ou nos “países em desenvolvimento", fazendo com que o discurso de soberania tenha um viés quando imposto pelo norte e outro quando visto através das epistemologias do sul.

\section{REFLEXOS DA EPISTEMOLOGIA DOMINANTE NO CONCEITO DE SOBERANIA DOS ESTADOS: UMA BREVE ANÁLISE DA SOBERANIA AMBIENTAL}

O conceito de soberania apresenta-se, na configuração atual do mundo, como um conceito ambíguo e impreciso. Entretanto, as primeiras delineações e definições para tal termo foram de fundamental importância não só para a construção e solidificação do princípio da territorialidade como também serviram de fundamento para o Direito Internacional em seus primórdios.

A noção de soberania ${ }^{21}$ como poder supremo que não reconhece outro acima de si remonta ao surgimento dos Estados Nacionais europeus. Há uma superação da estrutura organizacional da Idade Média, a qual se caracteriza pelo domínio universal do imperador e do papa, sendo que na Idade Moderna a sociedade internacional passa a ser composta por Estados Nacionais juridicamente independentes uns dos outros, mas igualmente soberanos.

Este é o fundamento básico da sociedade internacional pautada pelo modelo westfaliano. De acordo com David Held ${ }^{22}$, tal sistema, cuja consolidação foi marcada pela desigualdade e pela hierarquia (oeste dominando leste e norte dominando sul) tem algumas características relevantes: os Estados soberanos não são capazes de reconhecer nenhuma autoridade superior suas diferenças passam a ser resolvidas por intermédio da força e da violência - e o direito internacional se orienta seguindo regras mínimas de coexistência pacífica.

\footnotetext{
${ }^{21}$ As primeiras definições do tema surgiram no século XVI e foram de suma importância para a concepção da ideia de Estado Moderno. Jean Bodin, em 1576, na sua obra Les Six Livres de la République, apresentou a definição de que a soberania era um dos elementos indispensáveis à organização da sociedade política. Mais especificamente, em 1648, através de um acordo denominado "Paz de Westfália", o qual colocou fim na Guerra dos 30 anos na Alemanha, surgiram as bases para um modelo westfaliano de Estado e de sociedade internacional Partindo-se deste conceito, no panorama do Estado Moderno, a soberania é caracterizada por ser absoluta e perpétua.

${ }^{22}$ HELD, David. La democracia y el orden global: del Estado moderno al gobierno cosmopolita. Barcelona: Paiodós Ibérica, 1997.

REDESG / Revista Direitos Emergentes na Sociedade Global - www.ufsm.br/redesg v. 1, n. 2, jul.dez/2012 Revista do Programa de Pós-graduação em DiReIto da Universidade Federal de SANTA MARIA - www.ufsm.br/ppgd
} 
Até o termino da $2^{\mathrm{a}}$ Guerra Mundial, a sociedade internacional era regida por este modelo clássico westfaliano de organização. Todavia, diante da criação da Organização das Nações Unidas (ONU) e das preocupações surgidas com o pós-guerra, criou-se um marco para a aplicação e consolidação de um novo modelo de direito e governabilidade internacional. Segundo Ferrajoli ${ }^{23}$, tanto a Carta da ONU de 1945 quanto a Declaração Universal dos Direitos do Homem de 1948 foram os marcos teóricos responsáveis pela transformação da ordem jurídica do mundo, ao menos no plano normativo. Assim, a soberania externa ${ }^{24}$ dos países deixou de ser uma liberdade absoluta e passou a ser subordinada aos imperativos da paz e à tutela dos direitos humanos ${ }^{25}$.

Atualmente, o conceito clássico de soberania não se encaixa mais nos anseios e pressupostos do mundo globalizado, em que as relações de dependência entre os Estados e a existência de um direito internacional acabam por relativizá-lo. Segundo Held ${ }^{26}$ soberania atualmente pode ser conceituada como uma faculdade dividida entre múltiplos agentes nacionais, regionais e internacionais - e limitada pela natureza desta pluralidade.

Neste viés, surge o que alguns determinam de crise do Estado-Nação, uma vez que a globalização neoliberal, caracterizada, sobretudo, por uma economia mundial de internacionalização da produção e das transações financeiras, limita a autonomia e menospreza progressivamente a soberania dos Estados. Todavia, mesmo diante desta crise e mesmo de modo reduzido, o Estado continua existindo. Segundo, Boaventura de Sousa Santos o Estado Nação continua existindo, entretanto, deixa de ser centralizador e passa a ser um articulador/coordenado, pois é interesse para a manutenção do neoliberalismo a existência do Estado, desde que este se molde aos interesses do capital e flexibilize o seu conceito de soberania.

\footnotetext{
${ }^{23}$ FERRAJOLI, Luigi. A soberania no mundo moderno: nascimento e crise do Estado nacional. Tradução Carlo Coccioli e Márcio Lauria Filho. São Paulo: Martins Fontes, 2007.

${ }^{24}$ De acordo com Luigi Ferrajoli, a soberania pode ser dividida em interna e externa. A primeira, cujas formulações teóricas advieram das doutrinas de teóricos jusnaturalistas, como é o caso de Bodin e Hobbes, tem a função de definir e distinguir o poder do Estado, internamente, do poder de outras autoridades, sendo o Estado identificado como único centro de subordinação. No plano externo, as primeiras formulações de soberania remontam, juntamente com o nascimento do direito internacional moderno, aos teóricos espanhóis do século XVI, cujo objetivo era fornecer um fundamento jurídico à conquista do « Novo Mundo». Ibidem.

${ }^{25}$ Ibidem.

${ }^{26}$ HELD, David. La democracia y el orden global: del Estado moderno al gobierno cosmopolita. Barcelona: Paiodós Ibérica, 1997.

REDESG / Revista Direitos Emergentes na Sociedade Global - www.ufsm.br/redesg v. 1, n. 2, jul.dez/2012 Revista do Programa de Pós-graduaÇão em DiReITo da UnIVERSIDAde Federal de SANTA MARIA - www.ufsm.br/ppgd
} 
Justamente pelo jogo de forças e interesses típicos da fase neoliberal do capitalismo, há uma percepção latente na sociedade de que os governos obedecem aos bancos e não aos anseios de suas populações ${ }^{27}$. Nesta ótica, pode-se afirmar que mesmo diante da existência de normas e tratados internacionais de proteção aos direitos humanos e, por conseguinte aos direitos do meio ambiente, ainda impera no plano internacional uma dicotomia entre direito e soberania.

Com isso, aquilo que se encontra delineado no art. $2^{\circ}$ da Carta da Organização das Nações Unidas (ONU), qual seja, a igualdade soberana entre os Estados, apenas se efetiva no plano teórico, uma vez que no plano da prática, se desmantela pela desigualdade entre os Estados e pela prevalência de interesse dos mais fortes. A soberania, desta forma, além de relativizada em função dos efeitos da cooperação internacional, é também dependente, repartida e diferenciada. Neste viés, inclusive, adverte Eduardo Galeano ${ }^{28}$ que "o direito à independência e o direito à soberania são, na atualidade, um luxo dos países ricos. Quando os países pobres exercem seu patriotismo, esse é visto como populismo, ou pior ainda, em terrorismo.".

O discurso de Estado ou de Nação soberana se enfraquece mais ainda quando pensado dentro da lógica do Direito Internacional Ambiental e do universalismo do meio ambiente. A salvaguarda da natureza, que é um patrimônio comum da humanidade, faz parte dos direitos do homem e os problemas decorrentes da degradação ambiental escapam à soberania estatal.

Em função disso, ultimamente cresce o chamado direito de ingerência ecológica. 0 fundamento da existência de um direito de ingerência é o direito fundamental que todos têm de um ambiente ecologicamente equilibrado. No plano jurídico, Michel Bachelet ${ }^{29}$ define a ingerência ecológica como um direito ou um dever que se arrogam ou se impõem a vários Estados de irem examinar uma situação no interior de um ou de diversos Estados, sem a isso terem sido expressamente convidados. Justamente pelo fato de um Estado interferir no território de outrem sem sua expressa autorização, a ingerência configura-se como um elemento perturbador da soberania.

Evidentemente, é direito de todo ser humano o equilíbrio ecológico, havendo, portanto, a possibilidade de ingerência- a qual somente se concretiza com a materialização de uma intervenção de um Estado no território de outro. Todavia, há de se destacar que o discurso da

\footnotetext{
${ }^{27}$ BAVA, Silvio Caccia. Impasse na Rio +20. Le Monde diplomatique Brasil. Ano5/Número 59, 2012.

${ }^{28}$ GALEANO, Eduardo. A ordem criminosa do mundo. Depoimento. Documentário, TVE, Espanha, nov., 2008. Disponível em: <https://www.youtube.com/watch?v=GYHMC_itckg>. Acesso em: 24 jun. 2012.

${ }^{29}$ BACHELET, Michel. Ingerência ecológica: direito ambiental em questão. Tradução de Fernanda. Oliveira. Rio de Janeiro: Instituto Piaget, 1995.
}

REDESG / Revista Direitos Emergentes na Sociedade Global - www.ufsm.br/redesg v. 1, n. 2, jul.dez/2012 Revista do Programa de Pós-graduação em Direito da Universidade Federal de SanTa MaRIa - www.ufsm.br/ppgd 
epistemologia dominante e do neoliberalismo, por vezes, é o que se encontra por trás de algumas interpretações e aplicações do conceito.

Como efeito da denominada globalização perversa ${ }^{30}$, que é o ápice do processo de internacionalização do mundo capitalista, encontra-se aquilo que Boaventura de Sousa Santos ${ }^{31}$ denomina como globalismo localizado. Neste, são imperativos os efeitos impactantes provocados por práxis e comandos internacionais sobre determinadas culturas locais, que se desestruturam e se veem constrangidas a se adequar a estes imperativos globais (como por exemplo, desmatamento e degradação ambiental para pagar a dívida externa).

A crítica que se faz é que, em diversas vezes, o motivo real de ingerência não é o de efetivamente intervir em um país para proteger o meio ambiente e os recursos naturais, que são patrimônios comuns da humanidade. Pelo contrário, o real motivo são as forças dos jogos de poder do sistema capitalista e de sua atual faceta, o neoliberalismo.

Evidentemente, dentro do panorama das relações internacionais e de interdependência entre os Estados é impossível que o conceito clássico de soberania seja utilizado por um país para justificar a não aceitação de uma ingerência ecológica, sobretudo, se o real motivo da intervenção é efetivamente a proteção ambiental. Todavia, na sociedade neoliberal, o que predomina é a antítese entre capitalismo e democracia, de modo que a percepção que se tem é que tanto a democracia quanto o discurso de proteção ambiental são desafiados pelo poder e pelos interesses econômicos.

Reigota $^{32}$ observa que qualquer pessoa, com visão de desenvolvimento, sabe que é na biodiversidade que está a riqueza das próximas décadas e os países que a possuem devem fazer valer os seus interesses. Nesse sentido, a América Latina, que compreende seis dos 17 países biologicamente mais diversos do mundo - Brasil, Colômbia, Equador, México, Peru e República Bolivariana da Venezuela -, abrigando entre 30\% e 50\% das espécies de mamíferos, aves, répteis,

\footnotetext{
${ }^{30}$ SANTOS, Milton. Por uma outra globalização: do pensamento único à consciência universal. $20^{\mathrm{a}}$ ed. Rio de Janeiro: Record, 2011.

${ }^{31}$ SANTOS, Boaventura de Sousa. Para além do pensamento abissal: das linhas globais a uma ecologia de saberes. In: SANTOS, Boaventura de Sousa; MENESES, Maria Paula. Epistemologias do sul. São Paulo: Almedina, 2010.

32 REIGOTA, Marcos. Ecologia, elites e intelligentsia na América Latina: um estudo das suas representações sociais. São Paulo: Annablume, 1999.

REDESG / Revista Direitos Emergentes na Sociedade Global - www.ufsm.br/redesg v. 1, n. 2, jul.dez/2012 Revista do Programa de Pós-graduaçÃo em DiREITO dA Universidade FEderal de SANTA MARIA - www.ufsm.br/ppgd
} 
anfíbios e peixes do mundo, bem como uma alta proporção das espécies de plantas e insetos, tem força e, portanto, condições de negociar seus interesses ${ }^{33}$.

Justamente, em função disso, novamente se aplicam os ensinamentos de Boaventura de Sousa Santos acerca da necessidade de superação do pensamento abissal. As respostas para os graves problemas oriundos da crise financeira, a qual é uma crise sistêmica, cada vez mais são respostas fracas, as quais excluem alternativas oriundas de epistemologias dos denominados países do "Sul".

Prova disso é a grande dificuldade dos países da Europa e de os Estados Unidos assumirem e criarem para si metas de sustentabilidade ${ }^{34}$. Pelo contrário, quando o que está em jogo é uma ameaça ao rápido crescimento econômico, o engajamento e a participação em encontros que tendem a discutir meios alternativos para a proteção ambiental se tornam mais difíceis.

Por isso, como alternativa à lógica dominante do pensamento hegemônico, de lucro a qualquer custo, defende-se a importância de ações que privilegiem a denominada ecologia de saberes, ou seja, um diálogo e uma troca mútua de experiências entre as diferentes epistemologias existentes no globo. Defende-se, deste modo, a ideia de que a relativização da soberania dos mais diversos países não se dê somente em função dos interesses do capital e da economia mundial. Pelo contrário, quando se trata de direitos humanos e de proteção ambiental, deve ser válida a cooperação entre os países e a ruptura de fronteiras com vistas a aplicar o que será melhor para a proteção dos seres humanos e o equilíbrio do meio ambiente.

\section{CONCLUSÃO}

Procuramos neste sintético trabalho apresentar algumas constatações de uma pesquisa teórica ainda em fase inicial. Partindo de ideias de Boaventura de Sousa Santos e transpondo alguns conceitos do autor ao panorama ambiental, pode-se, de modo, claro visualizar como os

\footnotetext{
${ }^{33}$ Dados do documento-síntese $A$ sustentabilidade do desenvolvimento 20 anos após a Cúpula da Terra: avanços, brechas e diretrizes estratégicas para a América Latina e o Caribe. RIO+20. A sustentabilidade do desenvolvimento 20 anos após a Cúpula da Terra: Avanços, brechas e diretrizes estratégicas para a América Latina e o Caribe. Relatório. Rio de Janeiro, 08 jun. 2012. Disponível em: < http://rio20.net/pt$\mathrm{br} /$ documentos/a-sustentabilidade-do-desenvolvimento-20-anos-apos-a-cupula-da-terra >. Acesso em: 09 ago. 2012.

${ }^{34}$ BAVA, Silvio Caccia. Impasse na Rio +20. Le Monde diplomatique Brasil. Ano5/Número 59, 2012.
}

REDESG / Revista Direitos Emergentes na Sociedade Global - www.ufsm.br/redesg v. 1, n. 2, jul.dez/2012 Revista do Programa de Pós-graduação em Direito da Universidade Federal de Santa MaRIa - www.ufsm.br/ppgd 
ideais e necessidades do sistema capitalista se estendem à esfera ecológica, uma vez que os discursos da epistemologia dominante do Norte predominaram durante a Rio+20.

Desta maneira, a conclusão inicial a que se chegou é que a crise econômica internacional também se reflete na esfera ambiental, sendo que a resposta oferecida pelos governos, dentro dos moldes de um pensamento ortopédico, é a de um "capitalismo verde", no sentido em que busca atrelar a lógica do lucro capitalista à proteção ambiental.

Neste sentido, vislumbra-se que até mesmo o conceito de soberania, já relativizado, encolhe-se ainda mais diante do chamado direito de ingerência ecológica, exercido, sobretudo, dentro das interpretações da epistemologia dominante, vez que aplicado pelo "Norte" nos países do "Sul", detentores de grande parte dos recursos naturais. Estes, contudo, diante de sua biodiversidade, tem chances de empreender combate por reformas imediatas no capital, procurando caminhos para ir além do capitalismo.

Destarte, como conclusão preliminar, concorda-se com a proposta de Boaventura de Sousa Santos de uma alternativa contra hegemônica para o fenômeno visualizado. Iniciativas da sociedade civil, como é o caso do Fórum Social Mundial e da Cúpula dos Povos são instrumentos iniciais e de suma importância para, sobretudo em momentos de crise, intensificar a luta por novas relações políticas, demográficas e culturais, com vistas não só à superação do pensamento abissal, mas também a construção de uma sociedade verdadeiramente sustentável.

\section{REFERÊNCIAS}

BACHELET, Michel. Ingerência ecológica: direito ambiental em questão. Tradução de Fernanda. Oliveira. Rio de Janeiro: Instituto Piaget, 1995.

BAVA, Silvio Caccia. Impasse na Rio +20. Le Monde diplomatique Brasil. Ano5/Número 59, 2012.

BOBBIO, Norberto. A era dos direitos. Trad. Carlos Nelson Coutinho. Rio de Janeiro: Campus, 1992.

FERRAJOLI, Luigi. A soberania no mundo moderno: nascimento e crise do Estado nacional. Tradução Carlo Coccioli e Márcio Lauria Filho. São Paulo: Martins Fontes, 2007.

FOLADORI, Guilhermo Ricardo. O Capitalismo e a crise ambiental. Raízes - Revista de ciências sociais e econômicas, v. 19, p. 117-125, maio 1999. Disponível em:

<http://www.ufcg.edu.br/ raizes/artigos/Artigo_42.pdf >. Acesso em: 16 jul. 2012.

REDESG / Revista Direitos Emergentes na Sociedade Global - www.ufsm.br/redesg v. 1, n. 2, jul.dez/2012

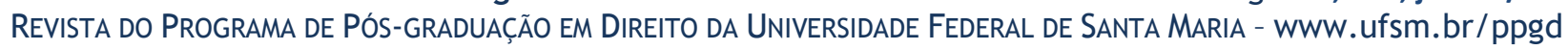


FURTADO, Celso. Reflexões sobre a crise brasileira. In: ARBIX, Glauco et al. (orgs.). Razões e ficções do desenvolvimento. São Paulo: UNESP; Edusp, 2001.

GALEANO, Eduardo. A ordem criminosa do mundo. Depoimento. Documentário, TVE, Espanha, nov., 2008. Disponível em: <https://www.youtube.com/watch?v=GYHMC_itckg>. Acesso em: 24 jun. 2012.

HARRIBEY Jean-Marie. Marxismo ecológico ou ecologia política marxiana? Dictionnaire Marx contemporain (sob a direcção de Bidet J., Kouvélakis), Paris, PUF, Actuel Marx Confrontation, 2001, p. 183-200. Trad. Fernando Ic. Martins. Disponível em: <http://resistir. info/ ambiente/ecologia_politica.html\#asterisco>. Acesso em: 16 abr. 2012.

HELD, David. La democracia y el orden global: del Estado moderno al gobierno cosmopolita. Barcelona: Paiodós Ibérica, 1997.

MAZZUOLI, Valério de Oliveira. Curso de Direito Internacional Público. 5. Ed. São Paulo: Editora Revista dos Tribunais, 2011.

PNUMA. Rumo a uma Economia Verde: caminhos para o desenvolvimento sustentável e a erradicação da pobreza. Relatório. Disponível em <

http://www.unep.org/greeneconomy/Portals/88/documents/ger/GER_synthesis_pt.pdf >. Acesso em 10 de out. 2012.

REIGOTA, Marcos. Ecologia, elites e intelligentsia na América Latina: um estudo das suas representações sociais. São Paulo: Annablume, 1999.

RIO+20. A sustentabilidade do desenvolvimento 20 anos após a Cúpula da Terra: Avanços, brechas e diretrizes estratégicas para a América Latina e o Caribe. Relatório. Rio de Janeiro, 08 jun. 2012. Disponível em: < http://rio20.net/pt-br/documentos/a-sustentabilidade-dodesenvolvimento-20-anos-apos-a-cupula-da-terra >. Acesso em: 09 ago. 2012

SANTOS, Boaventura de Sousa. Para além do pensamento abissal: das linhas globais a uma ecologia de saberes. In: SANTOS, Boaventura de Sousa; MENESES, Maria Paula. Epistemologias do sul. São Paulo: Almedina, 2010.

SANTOS, Boaventura de Sousa. Um Ocidente não-ocidentalista? A filosifia à venda, a douta ignorância e a aposta de Pascal. In: SANTOS, Boaventura de Sousa; MENESES, Maria Paula. Epistemologias do sul. São Paulo: Almedina, 2010, p. 528.

SANTOS, Milton. Encontro com Milton Santos ou o mundo global visto do lado de cá. Direção de Silvio Tendler. Documentário. Caliban Produções, Brasil, 2006.

SANTOS, Milton. Por uma outra globalização: do pensamento único à consciência universal. $20^{\mathrm{a}}$ ed. Rio de Janeiro: Record, 2011.

Recebido em: 18.11.2012 / Aprovado em: 18.02.2013

REDESG / Revista Direitos Emergentes na Sociedade Global - www.ufsm.br/redesg v. 1, n. 2, jul.dez/2012 Revista do Programa de Pós-graduação em DiReITO da Universidade Federal de SANTA MARIA - www.ufsm.br/ppgd 